\title{
EDITORIAL
}

\section{Public risk from tasers: Unacceptably high or low enough to accept?}

\author{
Christine A. Hall, MD, MSc
}

\begin{abstract}
See related article on page 90
\end{abstract}
VERSION FRANÇAISE À LA PAge 87

$\mathrm{T}$ asers, like nuclear weapons, haloperidol, fireworks, and even scissors, can be dangerous in untrained hands. However, banning tasers will not necessarily make the public safer. Despite the controversy surrounding taser use in North America, the question surrounding taser use should not be "Is it safe?" but, rather, "Is it as safe as, or safer than, the alternatives?"

In this issue of CJEM, Han and colleagues ${ }^{1}$ report a case of ocular trauma sustained from a taser. It is possible that the injury described in this case will add to the continuing controversial calls by some that conducted energy weapons (CEWs), like the taser, be prohibited. But before we throw out the baby with the bathwater, let's reconsider our options.

Emergency physicians are well aware of the difficulties and risks in managing violent and unstable patients. Like the police, we cannot always follow an orderly linear progression, beginning with dialogue and systematically following an algorithm of successively more invasive acts. Analogous to emergency airway management, the use of police force involves a very rapid assessment in an often deteriorating situation, with the best intervention being that which is most likely to completely control the situation while reducing, not eliminating, risk. Just as it is not necessarily appropriate to try an oral airway before an endotracheal tube, an attempt to gain hands-on physical control is not necessarily an appropriate initial use of force by a police officer in an unstable situation. ${ }^{2}$
Gaining control of a violent or disoriented individual is a challenging scenario in which the unpredictable risk is affected by numerous factors involving the individual, the environment and the intervention. Adverse outcomes, including death, are possible. In any dynamic, unstable scenario, the risk must be weighed against the need to gain physical control, prevent injury to others and limit the destruction of property. Even the risk of death can remain acceptable in the context of other immediate and measurable dangers. Considering this also requires knowledge of the risks of other modalities, including the use of batons, impact weapons and firearms, this raises the still partially unanswered question, "What are the risks of CEW use by police?" and the more important question, "Is it as safe as, or safer than, the alternatives?" If only the negative outcomes of any single restraint method are published, then the popular media, and even our medical journals, may distort the risk of adverse outcomes with the use of force. Without a careful analysis of all use of CEWs and force, the perceived level of risk can be overblown.

Data collection of CEW use and other police restraint methods has begun in Canada and the United States, but these efforts should be standardized and expanded. Independent, prospective analysis of injury patterns has begun to delineate the risk profile of the taser, and early reports are favourable. Bozeman and colleagues, ${ }^{3}$ in data presented at the 39th Scientific Assembly of the American

From the Department of Emergency Medicine, Vancouver Island Health Authority, Vancouver, BC; Clinical Assistant Professor, Department of Surgery, University of British Columbia, Vancouver, BC; Associate Professor, Faculty of Community Health Sciences, University of Calgary, Calgary, Alta.

All editorial matter represents the views of the authors and not necessarily those of CJEM or the Canadian Association of Emergency Physicians.

CJEM 2009;11(1):84-6 
College of Emergency Physicians in 2007, found that in 962 field applications of the TASER (TASER International) by 6 US law enforcement agencies, $99.7 \%$ of subjects sustained no or mild injury $(95 \%$ confidence interval [CI] 99.1-99.9). Three individuals sustained moderate or severe injury: 1 with rhabdomyolysis, 1 with a cerebral contusion and 1 with an epidural hematoma. There were 2 in-custody deaths, both of which were deemed to be unrelated to taser use after a review of case details and autopsy findings by the study investigators. Even if those 2 deaths were included in the severe outcome category, the proportion of subjects with no or mild injury following taser use in the field was $99.4 \%$ (95\% CI 98.8-99.8) and the proportion with moderate or severe injury becomes $0.5 \%$ (95\% CI 0.2-1.2).

Similarly in Canada, a preliminary review of Calgary Police Service data (2005-2007) indicates that police use of force occurs in only $0.07 \%$ (about 1 in 1400) of face-toface police-public interactions and that taser deployment on 271 individuals resulted in no deaths, and no or minor injury in 236 cases $(87 \%, 95 \%$ CI 82.5-90.8). Of the remaining 35 individuals, 3 were admitted to hospital (1.1\% of the total taser cohort, 95\% CI 0.2-3.2) and these cases are under review to determine whether they were associated with the taser deployment. This study will soon expand to include numerous police agencies throughout Canada and the United States.

Previously, deaths have been reported from the use of physical restraint (e.g., neck restraint, hog-tying, multiple officer restraint) and even pepper spray; deaths following police use of force are not necessarily taser-specific. The current calls for suspension of taser use completely disregard the findings of a very low actual risk associated with taser use in the field. Even the deaths that have occurred following taser application cannot be considered outside a broader context. We still do not fully understand the role of the controversial concept of excited delirium, and the causal role (if any) that CEWs or other force options play in deaths involving restraint.

Some have suggested that CEW use simply be suspended until "further research is available on the safety of the device." ${ }^{5,6}$ However, such research cannot be based on more study of healthy volunteers or animal models. Police agencies should continue to use the taser and collect rigorous data while they do so. Otherwise, we eliminate a reasonably safe option without learning the relative risk of known injurious alternatives like batons, firearms or unproven restraint methods.

As of Nov. 4, 2008, 28 Canadian men have died at some point following police use of a taser (Steve Palmer, Canadian
Police Research Centre, Ottawa, Ont.: personal communication, 2008). Yet reporting of police use of force in Canada is not standardized, it does not cross agency boundaries and no national database for in-custody deaths exists. The lack of anatomical data surrounding dart placement in the field precludes the ability to interpret animal studies that suggest paracardiac dart placement increases the risk of arrhythmia. ${ }^{7.8}$ Documentation that includes injuries and subject behaviour leading to the use of force or variations from policy needs to be standardized and collected in a national registry.

Industry-independent researchers need access to national records on police use of force. Accurate data that is independent of the information obtained from manufacturers would allow police agencies and policy-makers to objectively evaluate safety. Appropriate evaluation of real risk would limit the possibility of abrupt, reactive policy decisions generated in response to anecdote or misinterpretation of medical literature. ${ }^{9}$

Good information has a price, but funding must also be independent from industry. Government and other agencies that recommend research be conducted should provide funding for these initiatives. ${ }^{5,69-11}$ Subsidies from CEW manufacturers, regardless of transparency, is not an acceptable alternative given the obvious conflicts that exist. Involvement from interested physicians is also essential. We must accept this responsibility. The creation of a national physician's working group with an interest in in-custody injury and death would bring expertise to the debate and offer a neutral alternative to the assertive industry responses to medical journal publications on CEWs. ${ }^{12-14}$

The taser is a weapon, and all weapons have risks. But in trained hands, it's also a tool, and emergency physicians are familiar with tools that have risks. To remain free from the potential for industry bias and public alarm, we need national-level research on CEWs and other force modalities. The safety of our citizens and our police officers is at stake. Now is the time.

Competing interests: Dr. Hall is the principal investigator of the RESTRAINT Study, a prospective, multicentre study of persons undergoing police restraint and of the SCAPGAS Study, which seeks to determine whether an alternate method for the procurement of capillary blood gases can be developed for use in agitated, combative and often handcuffed patients in the prehospital setting. Funding for both these studies was provided by the Canadian Police Research Centre. Dr. Hall is also carrying out a 10-year review of custody death in Alberta with the cooperation of the Alberta Solicitor General and the Office of the Chief Medical Examiner of Alberta. This is funded in part by the Canadian Police Research Centre. Dr. Hall has no affiliation, financial or otherwise, with TASER International. 


\section{References}

1. Han JS, Chopra A, Carr C. Ophthalmic injuries from a TASER. CJEM 2009;11:90-3.

2. Canadian Association of Chiefs of Police, Board of Directors. A national use of force framework. Ottawa $(\mathrm{ON})$ : The Association; 2000. Available: http://ilecnet.org/Standards/Canada\%20National $\% 20$ Use \%20of\%20Force\%20Model\%202000.pdf (accessed 2008 Nov 24).

3. Bozeman WP, Winslow JE, Hauda WE II, et al. Injury profile of TASER electrical conducted energy weapons (CEWs). 39th Scientific Assembly of the American College of Emergency Physicians. Seattle (WA): Oct 8-11, 2007.

4. Butler C. Force Science News \# 102. Mankato (MN): Force Science Research Center; 2008. Available: www.forcescience news.com/home/current.html (accessed 2008 Nov 24).

5. Amnesty International. Amnesty International's continuing concerns about taser use. London (UK): Amnesty International; 2008. Available: www.amnesty.org/en/library/asset/AMR51/030 /2006/en/dom-AMR510302006en.pdf (accessed 2008 Nov 24).

6. American Civil Liberties Union. Citizen deaths in police custody, ACLU of Colorado call for limits on use of electroshock weapons. New York (NY): The Union; 2004. Avaialble: www .aclu.org/crimjustice/gen/10119prs20040226.html (accessed 2008 Nov 24)

7. Nanthakumar K, Billingsley IM, Masse S, et al. Cardiac electrophysiological consequences of neuromuscular incapacitating de- vice discharges. J Am Coll Cardiol 2006;48:798-804.

8. Dennis AJ, Valentino DJ, Walter RJ, et al. Acute effects of Taser X26: discharges in a swine model. J Trauma 2007;63:581-9.

9. Kiedrowski J, Petrunik M, Melchers R. An independent review of the adoption and use of conducted energy weapons by the Royal Canadian Mounted Police. Ottawa (ON): Royal Canadian Mounted Police; 2008. Available: www.rcmp-grc.gc.ca.ccaps /cew/kiedrowski_report_e.htm (accessed 2008 Nov 24).

10. Braidwood Inquiry Media Release. Victoria (BC): Province of BC; 2008. www.braidwoodinquiry.ca/

11. Breitkreuz G. Report of the Standing Committee on Public Safety and National Security: study of the conductive energy weapon - TASER. Ottawa (ON): House of Commons Canada; 2008. Available: www2.parl.gc.ca/Content/HOC/Committee /392/SECU/Reports/RP3582906/392_SECU_Rpt04_PDF/392 _SECU_Rpt04-e.pdf (accessed 2008 Nov 24).

12. Luceri RM. An open letter to the law enforcement community. Florida Arrhythmia Consultants. J Am Coll Cardiol 2007;49:732.

13. Kroll MW, Calkins H, Luceri RM. Electronic control devices and the clinical milieu. J Am Coll Cardiol 2007;49:732-3.

14. Kroll MW, Calkins H, Luceri RM, et al. Electronic control devices. CMAJ 2008;179:342-3.

Correspondence to: Dr. Christine Hall, Vancouver Island Research, 1952 Bay St., Memorial Pavilion, Kenning Wing 1, Victoria BC V8R 1J8; chris.hall@cprc.org 